Case Report

\title{
Loperamide Induced Torsades de Pointes: A Case Report and Review of the Literature
}

\author{
O. Mukarram, ${ }^{1}$ Y. Hindi, ${ }^{1}$ G. Catalasan, ${ }^{2}$ and J. Ward ${ }^{3}$ \\ ${ }^{1}$ Department of Internal Medicine, Texas Tech University Health Sciences Center, Permian Basin, USA \\ ${ }^{2}$ Department of Critical Care, Texas Tech University Health Sciences Center, Midland Memorial Hospital, Midland, TX, USA \\ ${ }^{3}$ Department of Clinical Pharmacology, Medical Center Hospital, Odessa, TX, USA
}

Correspondence should be addressed to O. Mukarram; osama.mukarram@ttuhsc.edu

Received 2 January 2016; Accepted 1 February 2016

Academic Editor: Alexander Bauer

Copyright (C) 2016 O. Mukarram et al. This is an open access article distributed under the Creative Commons Attribution License, which permits unrestricted use, distribution, and reproduction in any medium, provided the original work is properly cited.

\begin{abstract}
Abuse of over the counter drugs often gets overlooked by health care providers. Loperamide is one such over the counter drug that is often abused by drug addicts. We present here a case of a young male attaining euphoria from taking massive doses of loperamide. He developed Torsades de Pointes and subsequent cardiac arrest. We found similarities in the progression of myocardial electrical conduction abnormalities among loperamide and other previously known arrhythmogenic drugs. We intend to raise concern over the ease of availability of such drugs over the counter and increase the index of suspicion for over the counter drug abuse from our experience.
\end{abstract}

\section{Introduction}

Loperamide is an antimotility opioid agonist deemed safe owing to its $\mu$ receptor specificity and low abuse potential. It inhibits intestinal peristalsis and decreases fluid and electrolyte loss making a potent antidiarrheal agent commonly available over the counter. Adverse effects like constipation, nausea, and cramping are reported in less than $5 \%$ patients taking the prescribed dose of loperamide [1]. Previously cardiovascular side effects of loperamide were only reported as overdose cases in children [2]. However, recent literature has reported cases of cardiotoxic side effects in adults using high doses of loperamide to attain a euphoric state.

\section{Case Presentation}

A 26-year-old male, with history of heroin abuse, was brought to the ER after a transient episode of loss of consciousness. His vital signs upon arrival were heart rate of 50 beats $/ \mathrm{min}$, blood pressure of $125 / 60 \mathrm{mmHg}$, respiratory rate of 14 breaths/minute, and temperature of $98.9^{\circ} \mathrm{F}$. He was lethargic and had symmetrical constricted pupil bilaterally, absent bowel sounds, and a normal neuromuscular, cardiac, and respiratory exam. His initial laboratory tests showed sodium of $142 \mathrm{mmol} / \mathrm{L}$, potassium of $4.2 \mathrm{mmol} / \mathrm{L}$, calcium of $9.1 \mathrm{mg} / \mathrm{dL}$, and magnesium of $1.8 \mathrm{mg} / \mathrm{dL}$; extended urine drug screen was positive only for opiates. Blood alcohol level was within normal limits. No abnormalities were noted on CT scan of the head. EKG showed sinus bradycardia with normal PR, QRS, and QT/QTc intervals (Figure 1). Soon after presentation he developed shortness of breath, diaphoresis, and sustained ventricular tachycardia with ventricular rate of 220 beats/minute. He was defibrillated 2 times with $200 \mathrm{~J}$ before sinus bradycardia was attained again. After defibrillation his bradycardia worsened with heart rate of 40 beats/min; however, the patient remained symptom-free. Over the course of one hour he had 2 episodes of selflimiting Torsades de Pointes (TdP) each lasting less than 10 seconds and a third ending up in pulseless ventricular tachycardia (Figure 2 shows one such episode of TdP caught on telemetric monitoring). He was defibrillated again and prompt CPR was initiated. Pulse was regained immediately and he continued to have sinus bradycardia with heart rate of 40 beats/minute. He was given $2 \mathrm{gm}$ of magnesium IV and overdrive pacing was started with isoproterenol. A goal heart rate of 90 beat/minute was maintained for 


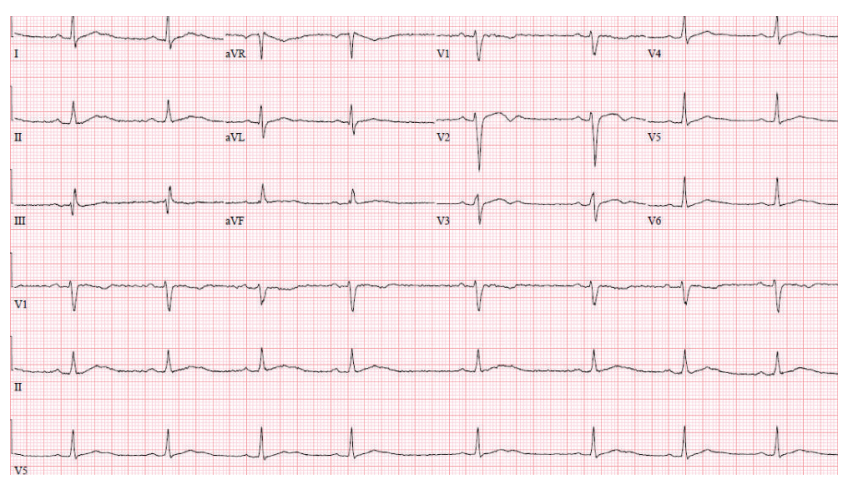

FIGURE 1: EKG on presentation showing sinus bradycardia with HR 50 bpm, PR interval 198 ms, QRS duration $122 \mathrm{~ms}$, QTc interval $371 \mathrm{~ms}$, and QT interval $408 \mathrm{~ms}$.

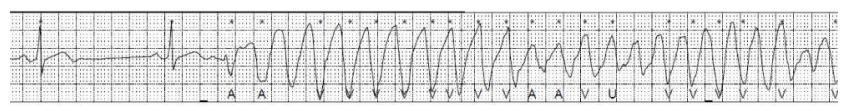

Figure 2: The figure shows the telemetry strip of our patient as he developed TdP.

48 hours. No further ventricular arrhythmias were noted; once isoproterenol was discontinued his heart rate remained between 50 and 60 beats $/ \mathrm{min}$. Transthoracic echocardiogram showed a normal left ventricular ejection fraction and no valvular or structural abnormalities. Cardiac angiography did not reveal any coronary pathology either. On day 3 of admission the patient admitted to taking loperamide for the past two months to relieve diarrhea associated with heroin withdrawal. Recently he had read on an internet blog that high doses of loperamide can give a similar "high" to heroin. A day prior to admission he started increasing his daily dose of the medicine to attain a euphoric state. On the day of admission his maximum ingested dose reached up to $192 \mathrm{mg}$ of loperamide. At this point a serum loperamide level was sent that came back, $2 \mathrm{ng} / \mathrm{mL}$ (expected peak level after ingestion of $8 \mathrm{mg}$ oral dose is $2 \mathrm{ng} / \mathrm{mL}$ or less). The patient remained hemodynamically stable and was discharged to drug rehabilitation facility on day 8 of hospitalization.

\section{Discussion}

QTc prolongation, brady-arrhythmias, and $U$ waves have previously been reported in people abusing opioid drugs [3]. The cardiac dysrhythmia predisposing our patient to the development of QT interval prolongation and $\mathrm{TdP}$ was likely the persistent sinus bradycardia. Polymorphic VT has shown to occur in association with bradycardia or frequent electrical pauses [4]. Drug-induced TdP typically results from the development of early afterdepolarizations and triggered activities from prolonged repolarization. This is usually caused as a ventricular premature beat falls on a prolonged repolarization cycle. Typical feature of these TdP is an antecedent prolonged QT interval, particularly in the last sinus beat preceding the onset of the arrhythmia $[5,6]$. The antecedent QTc interval in our patient was more than $500 \mathrm{~ms}$ prior to development of TdP. Blockade of delayed rectifying $\mathrm{K}^{+}$channels on the His-Purkinje network and $\mathrm{M}$ cells in the heart predispose to creating heterogeneity in recovery from excitability. This creates a zone of functional refractoriness in the mid myocardial layer which forms the premise of the reentry needed to sustain TdP [7].

In rat cardiac-myocytes, opioid receptor stimulation has shown to inhibit $\beta 1$ and $\beta 2$ adrenergic receptor activity. This effect is a result of cross talk between signaling pathways involved. The opioid receptors are Gi/Go-coupled receptors, whereas the $\beta$ adrenergic receptors are Gs-coupled receptors. Hence the effect of opioid receptor stimulation is to restrict the inotropic and chronotropic effect of adrenergic stimulation on the heart [8]. Researchers have found mu, kappa, and delta opioid receptors on the human heart [9]. Similar adrenergic inhibition might have a role to play in the setting of opioid overdose in human cardiac-myocytes.

Marraffa et al's observation showed that drug levels could not be predicted with the ingested dose and neither could the correlation of serum levels to likelihood of toxicity be made [10]. Loperamide has very poor and variable bioavailability (roughly 10 to $20 \%$ ). In addition, loperamide decreases peristalsis, which can augment the systemic absorption by keeping the medication in the gastrointestinal tract for a longer period of time [1]. It is difficult to cause toxic effects while taking oral loperamide in therapeutic doses. However, as our patient took 96 tablets $(192 \mathrm{mg})$, the amount systemically absorbed would be astronomical compared to the norm. The half-life elimination of loperamide is 9-14 hours; therefore, it would take 70 hours for this drug to be eliminated from the body. Prolonged consumption of the drug may lead to development of fat depots of loperamide not accounted for in the serum levels [10]. On day 3 of hospitalization, our patient still had therapeutic levels of loperamide, suggesting that this level on presentation might have been considerably higher.

Loperamide overdose has been reported repeatedly and recent literature points towards a similar pattern of cardiotoxic effects of this drug. Our case shows the electrical evolution of this arrhythmia in overdose setting and sheds light on similarities between TdP induced by loperamide and previously studied cardiotoxic drugs.

\section{Conclusion}

Abuse of over the counter drugs is often overlooked by health care providers. We intend to increase the index of suspicion of such toxicities and raise concern about the safety profile of loperamide as it still remains easily available over the counter.

\section{Conflict of Interests}

The authors declare that there is no conflict of interests regarding the publication of this paper. 


\section{References}

[1] Lexicomp Online, Lexi-Drugs, Lexi-Comp, Hudson, Ohio, USA, 2014.

[2] T. Litovitz, C. Clancy, B. Korberly, A. R. Temple, and K. V. Mann, "Surveillance of loperamide ingestions: an analysis of 216 poison center reports," Journal of Toxicology: Clinical Toxicology, vol. 35, no. 1, pp. 11-19, 1997.

[3] J. Lipski, B. Stimmel, and E. Donoso, "The effect of heroin and multiple drug abuse on the electrocardiogram," American Heart Journal, vol. 86, no. 5, pp. 663-668, 1973.

[4] W. M. Jackman, K. J. Friday, J. L. Anderson, E. M. Aliot, M. Clark, and R. Lazzara, "The long QT syndromes: a critical review, new clinical observations and a unifying hypothesis," Progress in Cardiovascular Diseases, vol. 31, no. 2, pp. 115-172, 1988.

[5] R. Passman and A. Kadish, "Polymorphic ventricular tachycardia, long Q-T syndrome, and torsades de pointes," Medical Clinics of North America, vol. 85, no. 2, pp. 321-341, 2001.

[6] I. A. Khan, "Long QT syndrome: diagnosis and management," American Heart Journal, vol. 143, no. 1, pp. 7-14, 2002.

[7] Y. G. Yap and A. J. Camm, "Drug induced QT prolongation and torsades de pointes," Heart, vol. 89, no. 11, pp. 1363-1372, 2003.

[8] S. Pepe, O. W. V. Van Den Brink, E. G. Lakatta, and R.-P. Xiao, "Cross-talk of opioid peptide receptor and $\beta$-adrenergic receptor signalling in the heart," Cardiovascular Research, vol. 63, no. 3, pp. 414-422, 2004.

[9] P. Sobanski, M. Krajnik, M. Shaqura, E. Bloch-Boguslawska, M. Schäfer, and S. A. Mousa, "The presence of mu-, delta-, and kappa-opioid receptors in human heart tissue," Heart and Vessels, vol. 29, no. 6, pp. 855-863, 2014.

[10] J. M. Marraffa, M. G. Holland, R. W. Sullivan et al., "Cardiac conduction disturbance after loperamide abuse," Clinical Toxicology, vol. 52, no. 9, pp. 952-957, 2014. 


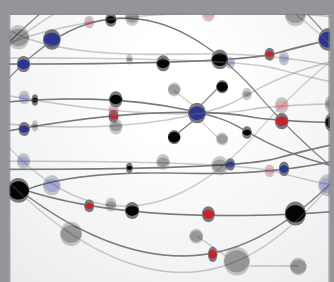

The Scientific World Journal
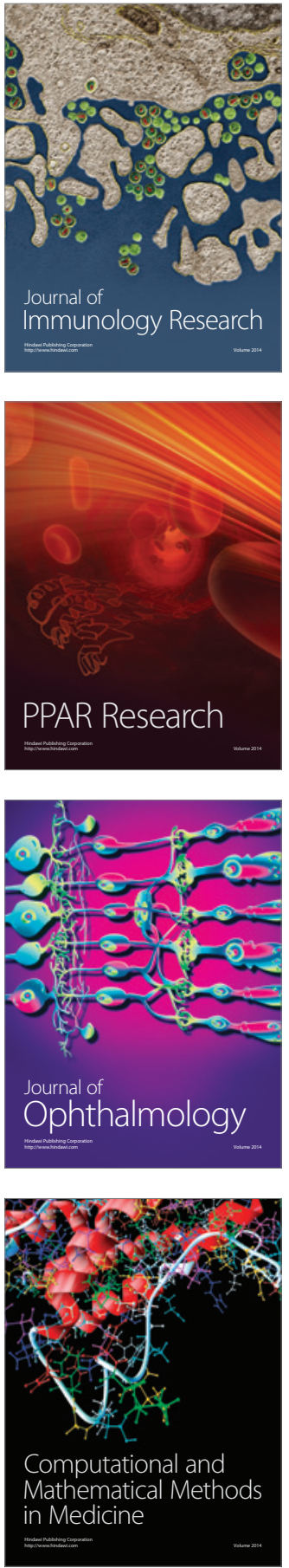

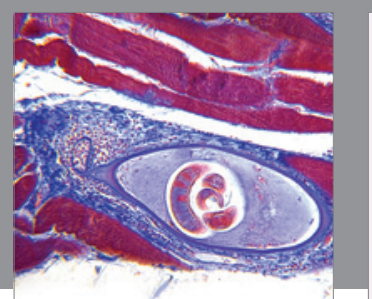

Gastroenterology Research and Practice

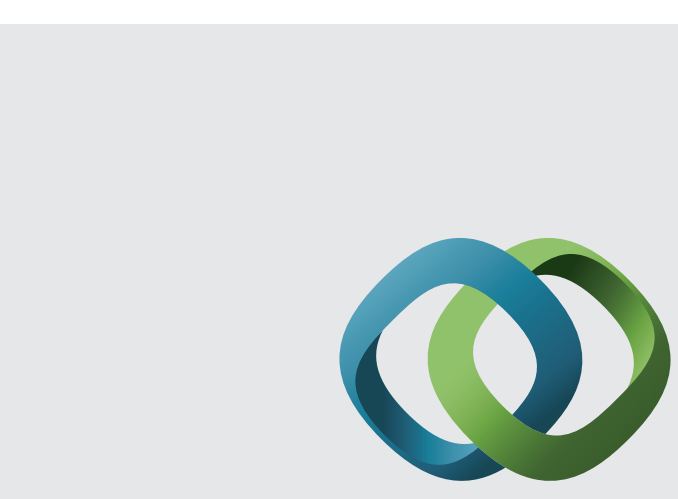

\section{Hindawi}

Submit your manuscripts at

http://www.hindawi.com
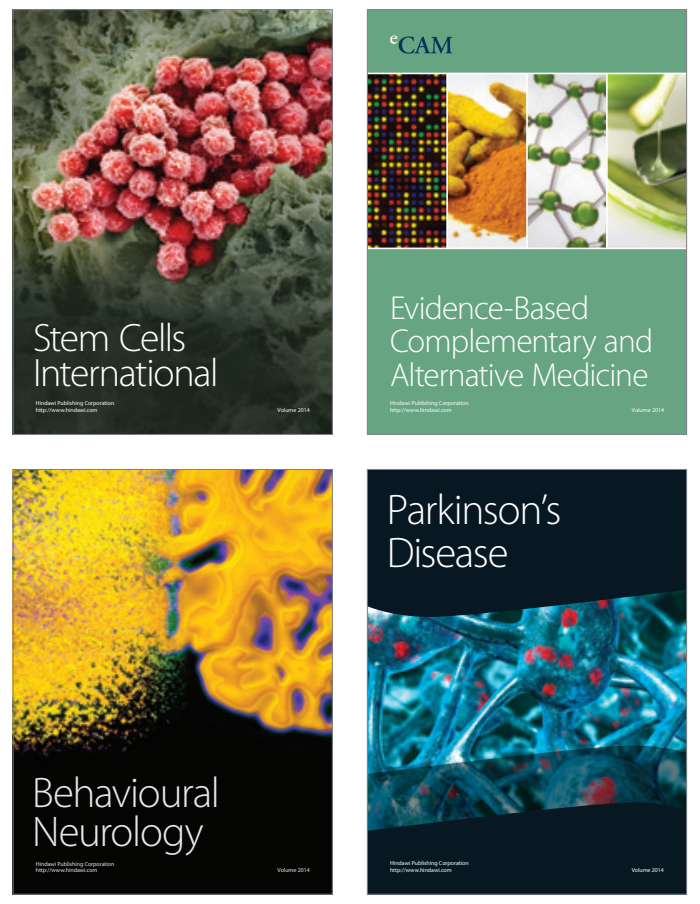
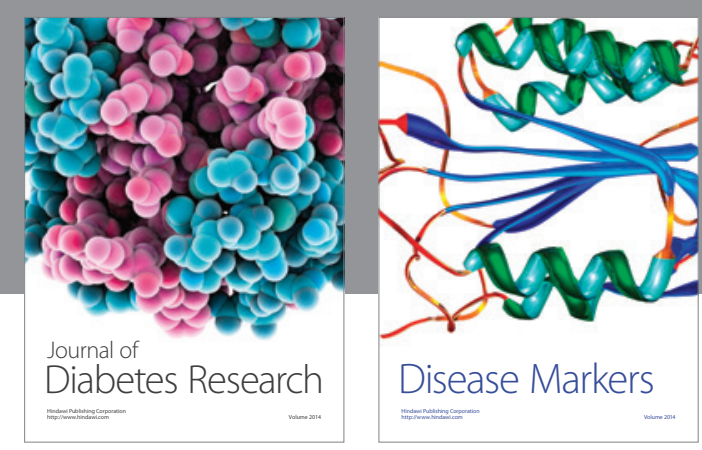

Disease Markers
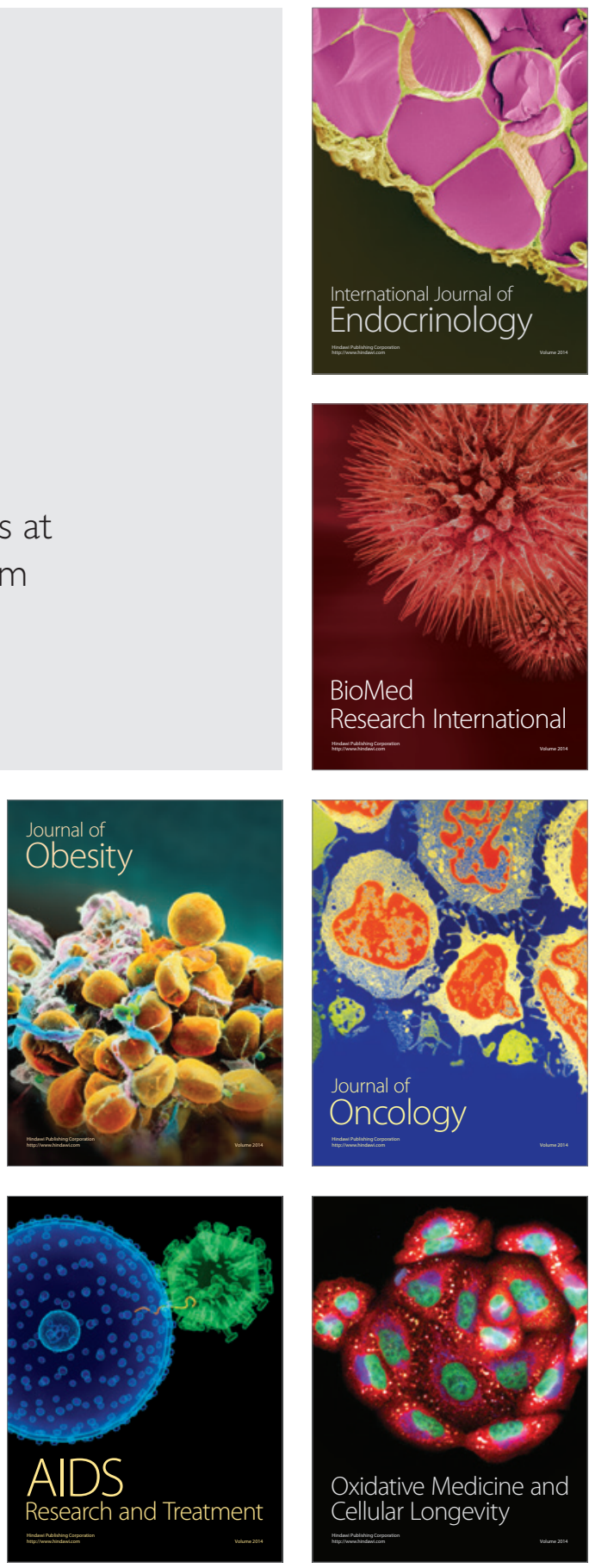